\title{
Commentary
}

\section{The Implications of the FCC's Net Neutrality Repeal}

\author{
Florian Schaub \\ School of Information, University of Michigan, Ann Arbor, MI 48109, US; E-Mail: fschaub@umich.edu
}

Submitted: 10 May 2018 | Accepted: 24 May 2018 | Published: 26 September 2018

\begin{abstract}
In December 2017, the Federal Communications Commission (FCC) repealed US net neutrality regulation. The author discusses the meaning and importance of net neutrality, the FCC's prior net neutrality rules and the implications of their repeal.
\end{abstract}

\section{Keywords}

Internet; net neutrality; public policy; regulation

\section{Issue}

This commentary is part of a multidisciplinary issue of Media and Communication, edited by Epp Lauk (University of Jyväskylä, Finland) and Raul Reis (Emerson College, USA).

(C) 2018 by the author; licensee Cogitatio (Lisbon, Portugal). This article is licensed under a Creative Commons Attribution 4.0 International License (CC BY).

\section{Introduction}

On December 14, 2017, the commissioners of the Federal Communications Commission (FCC) - the US regulatory agency for communications-voted to repeal the FCC's 2015 net neutrality regulation. The FCC's net neutrality repeal, as well as its prior regulations, were subject of heated public debate. So, what is net neutrality? What was repealed by the FCC? What are the implications of the FCC's net neutrality repeal?

\section{What is Net Neutrality?}

At its core, net neutrality is a principle requiring that the technology and entities that provide Internet connectivity and access should be impartial, or neutral, with respect to the communication and content for which that Internet access is used. This means that Internet service providers (ISPs) must treat all data and information on the Internet the same way (Krämer, Wiewiorra, \& Weinhardt, 2013). They cannot discriminate or charge differently for different content or depending on who is providing a service.

By clearly distinguishing between the provisioning of Internet connectivity and Internet content, net neutrality ensures equal access to online content regardless of who is providing or requesting information. Net neutrality prevents ISPs from abusing their powerful position as mediator between consumers and content providers. This provides benefits for both consumers and online companies: consumers pay their ISP for Internet access and regardless of which ISP they choose, they will have the same level of access to online services, websites and apps. Online companies benefit because net neutrality creates a level playing field among small and large competitors. A startup with a good idea can create a website or app and be confident that anyone will have the same opportunity to access their service as those of the big established online companies. Non-profit organizations, individuals, and content creators can make their content available to the world without having to worry who will or won't be able to access it. Net neutrality ensures the openness and fairness of the Internet as well as facilitates innovation online. Many countries have created net neutrality laws or regulation to protect these tenets of the Internet, notably both the United States and Europe adopted net neutrality regulation in 2015 .

\section{Net Neutrality and the FCC}

Not long after adopting net neutrality regulation for the United States in 2015, the FCC commissioners under FCC Chairman Ajit Pai voted in December 2017 to repeal the FCC's net neutrality regulation. This back and forth comes down to the question: Should ISPs be classified as common carriers or information services by the FCC? 


\subsection{The 2015 Net Neutrality Rules}

In 2015, the FCC reclassified broadband ISPs as a telecommunications service ("common carrier") under Title II of the Communications Act of 1934 and Section 706 of the Telecommunications Act of 1996 to establish broader regulatory power over ISPs. This was a reaction to a court ruling that struck down the FCC's previous net neutrality principles, because the FCC had until then classified ISPs as "information services" under Title I of the Communications Act, which according to the court did not provide the FCC with the authority to enact net neutrality regulation for ISPs (Verizon v. FCC). Those earlier rules were put into place after some U.S. ISPs started throttling video streaming services, such as YouTube and Netflix, unless they entered into paid agreements with the ISPs. ISPs were effectively charging twice for the same service: consumers paid for access to the Internet and content providers had to pay to ensure their content would get to the consumers.

The 2015 FCC net neutrality regulation, titled the FCC's Open Internet Order (Federal Communications Commission, 2015), reclassified ISPs as telecommunication services-public utility providers-and prohibited ISPs from blocking access to legal content; throttling or otherwise impairing lawful Internet traffic; and establishing "fast lanes" for paid prioritization of some Internet traffic over other. This last point, however, did not mean ISPs could not engage in reasonable network management, but it prevented ISPs from pressuring content providers to enter into paid prioritization agreements. The order further stipulated that ISPs may not "unreasonably interfere with or unreasonably disadvantage" consumers' selection, access and use of online information, or the companies which provide those services (also called edge providers). ISPs further needed to disclose their network management and other practices.

\subsection{The 2017 Net Neutrality Repeal}

What changed with the FCC's 2017 vote? By adopting an order called "Restoring Internet Freedom", the FCC repealed the 2015 net neutrality rules in favor of returning to a "light-touch regulatory scheme" of the Internet (Federal Communications Commission, 2018a). More specifically, the FCC reversed the classification of ISPs as telecommunications services (common carriers), thus giving up its Title II authority over ISPs. As a result, ISPs are no longer regulated as public utilities and are now free to block or throttle Internet traffic, as well as offer paid prioritization, as long as they disclose their network management practices. This order also fully moves responsibility for investigating unfair trade practices by ISPs to the Federal Trade Commission (FTC).

FCC Chairman Pai (2018) argued that this change was necessary, because the 2015 net neutrality rules placed a high burden on companies and prevented investments in communications infrastructure and innovation. The FCC (2018a) and Pai (2018) claim that the Internet worked fine and prospered without the net neutrality rules before 2015 , therefore no net neutrality regulation is required. Furthermore, they claim that the net neutrality repeal will help spur competition between ISPs and that competition will ensure fair and affordable access to the Internet across the United States.

\section{Implications of the FCC Net Neutrality Repeal}

Critics of the FCC's net neutrality repeal, myself included, do not share the FCC's optimistic outlook. The repeal of net neutrality heavily favors ISPs, with no benefits for consumers or even online companies. The FCC's net neutrality repeal places a lot of trust in ISPs to behave in consumer-friendly ways, which will likely amount to wishful thinking given ISPs track record in the United States. I expect that the implications of the FCC's net neutrality repeal will manifest through small and creeping changes rather than sudden shifts.

\subsection{Higher (Indirect) Costs}

The notion that the Internet prospered without much regulation and therefore does not need to be regulated going forward ignores the reality that ISPs in the United States have been increasingly exerting and abusing their powerful position as mediators between content (or edge) providers and consumers. It is very likely that ISPs will return to their practices of throttling high bandwidth services, such as video streaming, music streaming or video chatting, in order to pressure specific content providers into signing paid prioritization agreements to ensure access to the ISPs' networks and customers. Thus, without net neutrality ISPs can charge twice for the same service: their subscribers for Internet access and content providers for making sure that their data actually reaches the ISP's subscribers. While this may seem reasonable at first glance-after all those streaming services are bandwidth-intensive-an analogy reveals the absurdity of this situation. Imagine your power company would not just charge you for the electricity you use but in addition also require the manufacturer of your television, washing machine or electric car to pay any time one of their devices is used or charged, with the justification that watching TV or charging an electric car increases demand for electricity. While this is true, the customer is already paying for the use of this electricity! Similarly, Internet subscribers already have a paid agreement with an ISP that guarantees them a certain bandwidth and possibly transfer volume. ISPs additionally charging content providers for access to their customers constitutes "double dipping."

As a result, consumers may eventually end up paying more for online content, such as their Netflix subscriptions, because content providers would have to enter into separate agreements with different ISPs in the United States. 
While large online companies may be able to shoulder such costs and make advantageous deals with ISPs, smaller companies, startups, and non-profit organizations may suddenly be faced with high costs to ensure that their services make it to consumers. Thus, rather than fostering innovation, the net neutrality repeal may stifle innovation in the online space by making it much more expensive with little benefit to consumers.

\subsection{Bundled Offerings and Limited Internet Access}

While double dipping is an issue, an even more concerning implication of the net neutrality repeal is that ISPS now have almost free reign over what content their subscribers will have access to, for instance due to how ISPS offer and package Internet access. With so called zerorating offers, ISPs already exempt the use of certain online services from data caps.

Going forward ISPs may impose further requirements and charges for their zero-rating partners. The large U.S. ISPs have also become content providers through acquisitions of NBC Universal (by Comcast), Time Warner (by AT\&T) and other content providers. Thus, ISPs have strong incentives to give preferable treatment to their own content, as well as enter into mutual agreements with other entities that also control access to Internet subscribers or content subscribers.

Zero-rating may lead towards even more tailored and tiered bundled Internet access offerings. In the future, some online services may come for free with your basic Internet package due to respective agreements. If you want access to that other video platform you will have to get the extended package. You want access to the whole Internet? Sure, that's still available-just sign up for the premium package. In such a model, ISPs would effectively replicate the antiquated television channel model for Internet access.

Based on tiered pricing, ISPs could curate what online content and services most people will have access to, and which ones will only be available to those who are willing to and can afford to pay extra. People of low socioeconomic status may be especially disadvantaged by having less access to the full internet. While tiered access models may exacerbate socioeconomic differences, ISPS could also suppress certain websites and online services, as long as they transparently disclose those practices in their terms of service. This would have a detriment effect for equal access to online resources, with serious implications for access to knowledge, free speech, and democratic participation.

\subsection{Little Competition among ISPS}

While increased competition among ISPs in the United States would be welcome, there is little indication that the net neutrality repeal would substantially spur competition among ISPs or incentivize ISPs to substantially invest in improving their network infrastructure. In most parts of the United States, especially in rural areas, people have little to no choice regarding ISPs. According to a recent FCC report (Federal Communications Commission, 2018b), in 2016, 63.2\% of developed census blocks in the United States had only one cable provider, $4.1 \%$ had two or three, $32.7 \%$ had none. The report shows similarly sparse competition for other Internet access technologies.

This lack of competition among ISPs means that transparency about network management practices alone is not sufficient to protect consumers. Most U.S. consumers will not be able to switch ISPs if they disagree with their practices or pricing model. Furthermore, even if they are so lucky to be able to choose among two or three ISPs, that choice may not be meaningful if those ISPS implement similar network management practices. As long as those practices are made transparent and are not clearly deceptive or unfair-the only cases in which the FTC can become active-ISPs will be able to get away with throttling and other practices violating net neutrality.

\section{Conclusion}

While the FCC's net neutrality repeal constitutes a major setback for a neutral and open Internet, it will likely not mean the end of net neutrality in the United States. At the time of writing, multiple lawsuits against the FCC's decision have been filed by consumer advocacy groups, attorneys general from multiple U.S. states, as well as technology companies. Some states, including Washington and Oregon, have passed state laws prohibiting ISPS from blocking or throttling Internet traffic. In other states, including California and New York, net neutrality state laws have been introduced. The governors of New Jersey, Montana and other states have signed executive orders requiring ISPs to adhere to net neutrality principles if they do business with the state. Net neutrality bills have also been proposed in congress. In May 2018, the U.S. Senate voted to overturn the FCC's Restoring Internet Freedom Order, but at the time of writing it is doubtful whether the same vote would reach quorum in the House of Representatives. The FCC's net neutrality repeal was misguided and will hopefully be rectified in the United States and not replicated in other countries. Net neutrality is essential to ensure open exchange, free speech, and innovation online by preventing the entities that provide access to the Internet from discriminating among traffic, information, content providers or individuals.

\section{Conflict of Interests}

The author declares no conflict of interests.

\section{References}

Federal Communications Commission. (2015). Protecting and promoting the open Internet (80 FR 19737). Washington, DC: US Government. 
Federal Communications Commission (2018a). Restoring Internet freedom (83 FR 7852). Washington, DC: US Government.

Federal Communications Commission (2018b). Internet access services: Status as of December 31, 2016. Washington, DC: US Government.

Krämer, J., Wiewiorra, L., \& Weinhardt, C. (2013). Net neutrality: A progress report. Telecommunications Policy, 37(9), 794-813.

Pai, A. (2018). Statement of Chairman Ajit Pai Re: Restoring Internet Freedom (WC Docket No. 17-108). Washington, DC: Federal Communications Commission.

Verizon v. FCC 2014 11-1355 United States Court of Appeals for the District of Columbia Circuit.

\section{About the Author}

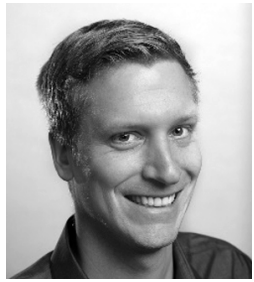

Florian Schaub is Assistant Professor of Information and Electrical Engineering and Computer Science at the University of Michigan. Dr. Schaub's research focuses on understanding and supporting people's privacy and security behavior and decision making in complex socio-technological systems. His research interests span privacy, human-computer interaction, and emergent technologies, such as the Internet of Things. Dr. Schaub received his doctoral degree in Computer Science from the University of Ulm, Germany. 